\title{
Due Process and Local Government Administration in Nigeria: A Conceptual Relationship
}

\author{
MukhtarShehuAliyu,Abdu Ja'afaruBambale \\ Department of Management Sciences, Kano State College of Arts And ScienceP.M.B. 3145, Kano-Nigeria \\ Department of Business Administration and Entrepreneurship,Bayero University, KanoKano - Nigeria
}

\begin{abstract}
The paper seeks to address issues relating to Due Process in Nigeria's local government administration. As part of its objectives it has examined what Due Process concept is all about and what constitute its main problems with particular reference to contract awards. In the paper literature is reviewed which provide some understanding on Due Process objectives, stages, requirements, benefits as well as problems associated with it implementation. A research framework is provided, which suggest empirical examination of Due process and local government administration in Nigeria.
\end{abstract}

Keywords: Due process, Local government administration, Nigeria.

\section{Introduction}

Due Process policy and principles have been with history and civilisation. Its principles have been in application that cut across all field of human endeavour i.e Law, Medicine, Management, Pharmacy, Accounting and the rest, and issues relating to it is not only peculiar to Nigeria (Christodolou, 2010). Similarly, in recent reform exercise world over, Due process has been modified to be applied in governance in order to check excesses and to ensure openness in the facilitation of government activities. Due process involves the observance of procedures; its implementation requires the contributions of all and sundry including Local government administrators. It should be noted that the reform processes as enshrined in the new public sector, financial management reform advocate, among others, for monitoring service delivery functions and providing reviews of the efficiency and effectiveness (value for money) of public services and program evaluation. It is also concerned devolvement / decentralisation or delegation of budgets. The reforms have tended to link budgets with the reporting of result in financial and non-financial terms. This development makes Hood cited in Sa'id (2009) to suggest that to enhance accountability in public governance, let there be no (lessen) differences between the public and private sectors and emphasis be shifted from process accountability to accountability in terms of results. In this vein, Due process is a device that facilitates achievement of optimum results and ensures best use of scarce resources and is considered as a mechanism for ensuring compliance with laid down rules and procedures that guide action, work or task. It is also a means of creating cost effectiveness.

Similarly, Okolie and Oghuma in Sa'id (2009) advocates that Due process and Value for money (VFM) are directly related. Value for money is a policy that seeks to maximize the use of scarce resources to achieve the desired goal at a low cost with high standard. The achievement of value for money depends on the existence of sound planning, appraisal, authorisation and control of the use of scarce resources. It is in line with this that this paper seeks to examine Due process in local government administration.

\subsection{Problem Statement}

The aim of the paper is to examine the conceptual relationship between Due process and local government administration in Nigeria. The motivation was as a result of Adedakun et.al (2013), study that recommended the need for selective tendering method so as to know the level of compliance in Due process. However, this gave birth to this conceptual paper starting from local government administration been the grass root.

\section{Literature Review}

It is generally agreed that Due process is an element of good governance and effective transparency. It is considered to be an effective mechanism for instituting strict compliance with openness, stimulating competition and ensuring as much as possible cost accuracy. According to Sa'id (2009), Due process system is predicted on certain rules and procedures that should guide contract award, establish transparent, competitive and fair procurement system. It is expected to stamp out bias in awarding contracts, to promote integrity and encourages spending within budgets.

According to him, Due process is ensured in order to enjoy the following merits:

- Recognition of only competent contractors for bids;

- Elimination of middlemen i.e. contract consultants; 
- Re-instatement of rightful contract winners formerly denied contract;

- Restoration of confidence of contracts

- Elimination of corruption culture

- Creation of massive savings; and

- Improvement in revenue collection units of governments.

\subsection{Objectives of Due Process}

A guideline on Due process for Local government (2006) in Kano State identified the following objectives:

a. To harmonize and update the policies and practice in public procurement;

b. To ensure that project conceptualisation, packaging and execution are in tandem with targets as contained in approved budgets;

c. To strictly enforce the Due process principles of transparency, competition, efficiency and value for money in the procurement of public goods, works and services;

d. To ensure that the execution of contract are monitored; and

e. To prevent extra-budgetary spending and inflationary of contract prices.

On a similar term, Apoti (2005) identified the objectives of Public Procurement Programme to include the following:

a. To establish a statutory and institutional framework for public sector procurement.

b. To establish clear-cut procedure to ensure credibility, integrity and transparency in contract award.

c. To institute control mechanism for the review of procedure in contract award.

d. To encourage competition that will ensure value for money by adopting international best practices in the award of contracts.

e. To prevent waste, inefficiency and above all, opportunities for corruption in the award of contracts.

\subsection{Stages in Due process}

The procedure observe in the award of contract depend largely on the category of the contract. In compliance with the Local government law (2006), the spending limits of the local administration are as follows:
a. Local Government Chairman --- N1.00- N250,000
Provided that it should not be more than four times in a month.
b. Local Government Council --- Expenditure not exceeding N5million in a month.
c. State Government ------------- Above N5million (through ministry for local government).

\subsubsection{Requirements for Due Process}

1- Advertisement: The advertisement is to be based on the scope of works and the approved expenditure limit, Local governments are required to advertise for prospective contractors/ suppliers to submit pre-qualification of bids. The advertisement should be in two categories:

i- Contract in the range of $\mathrm{N} 250,001$ to N5,000,000.

This is to be advertise through the medium of internal memo (notice) which should be posted on the notice board and published in the official Gazette.

ii- Contract above N5million.

In this category of contracts, the advertisement calling for pre-qualification of contractors shall be made in at least two (2) dailies and the official Gazette.

\section{2- Pre- Qualification Process and Criteria}

According to Warad and Broachner (2006), prequalification refers to possible ways of protecting able and well established firm with their client getting a more valuable and economical jobs. Theprocessensure that only invitation to bid is only given to firms who possessesadequate capabilities and resources to handle and execute projects (Aje, 2012). The proper execution of competitive bidding is dependent on contractors prequalification. The call for prequalification is one of the fundamental criteria for any project certification, Ezenwa (2004), cited in Adedokun, Ibironke and Babatunde (2013). When advertising for invitation of prospective contractors for prequalification of bids, Local administration are required to ensure conformity with standard format. This entails the following:

- Name and address of the procuring Local government;

- Brief description of the object of the procurement, including the desired time for delivery or completion;

- Scope of work;

- Summary of the required qualification criteria;

- Place and deadline for the submission of the application for pre-qualification; and 
- Date of availability of the pre-qualification documents.

All responses to the advertisement received within the stipulated time of not more than 21 days will be collected and evaluated.

\section{3- Analysis of Pre-Qualification Bid}

In Nigeria, the basic situations where open tendering methods are used are on governmentparastatals and agency projects which are financed with public money; hence they are advertised and tendered for. Ngai et al. (2002), opined that open tendering system gives room for accountability and removes the burden ofbiases as might be brought where selected list is drawn up.After collection from all the respondents to a pre-qualification advertisement, a committee called Tender Evaluation (TEC), shall analyse the return on some of the following criteria:

- Evidence of incorporation;

- Company's Audited Accounts for three years;

- Evidence of tax clearance for three years;

- Evidence of financial capabilities and/ or Banking support;

- Records of previous projects;

- Experience and Technical qualification of key personnel;

These are just few, all respondents will be scored and any one scoring $70 \%$ and above will be compiled in to a list of pre-qualification bidders. Competent bidders will be issued with invitation to tender or bid documents.

\section{4- Invitation to Tender / Bid}

After the analysis and evaluationprocedures as highlightedabove, the local administration shall immediately print and paste the list of the successful bidders that attained the benchmark. These are considered eligible for the issue of purchase of invitation forms to tender.

The tender document shall be in the standard format appropriately describing the goods or works to be undertaken. It most contains sufficient information to facilitate fair competition among the bidders for the process to be transparent. Furthermore, the tender document shall be returned not later than six (6) weeks from the date of issue.

\section{5- Opening of Tender Documents}

The tender/ bids must be opened immediately after the bidding period in the presence of all bidders or their representatives and the civil society.

6- Evaluation of Tender/ Bid

The local administration should establish a Tender Evaluation Committee (TEC), which shall consist of five members, three of which shall be experienced in procurement. The committee is expected to carefully assessed the submissions of the prospective bidders to determined their appropriateness/ compliance with the standard Technical and Financial requirements.

Local Government TEC shall consist of:

- Local Government Chairman ------------ Chairman

- Supervisory Councillor Works -------------- Member

- Director Personnel Management -------------- Member

- Treasurer --------------- Member

- HOD of the Department where the project in question is Relevant ------------- Secretary

\section{7- Selection of Winner(s)}

The bidder who is adjudged competent (technically) and quotes the lowest evaluated tender will be determine as the winning bidder.

\subsubsection{Conditional Issuance of a Due Process Certificate}

When the cost by an emerging winner in a right contract process is higher than the fair market cost, the issuance of a Due process certificate(clearance) for award shall be made conditional upon the alignment of the cost. In such circumstance the adjudged winner shall be advised through the procurement entity (Local government council), to realign the cost on offer to the compliance Review Estimated cost (vetted).

However, if such a winner fails, the offer will be made to the second bidder. In the event of an impasse involving all the bidders declining the offer, the Ministry for Local government May advice the local administration to cancel the exercise and re- advertise. 
The following should be considered in articulating a sound lists for tender as suggested by Ofong (1999), cited in Adedakun et.al (2013), which according to him should be reviewed from time to time. These includes:

- the standard of workmanship;

- the equipment, such as plant and machineries possessed by the firm, the size of

- the pay roll and the degree to which the firm sub-lets part of their previous work;

- the business records and standards - for example, whether the completion dates are met and whether there is any regular difficulty over supervision of quality orfinal settlements;

- the financial stability and the length of time in business;

- the capacity available in relation to current work load; and

- the willingness to tender

\subsubsection{Benefits of Due Process}

According to Goron-dutse (2009), the benefit associated with Due process among others includes:

- It enhances efficiency: Efficiency in the sense that, things will be place the way they are supposed. Efficiency in the management of all government undertaken i.e. award of contracts, effective monitoring and supervision as well as proper implementation of government budgets.

- Enhanced openness, transparency, competition, right costs, stoppage of projects abandonment e.t.c.

- Improve public procurement processes: The entire process of procurement will be improved, because there are conditions, guidelines, procedures and a number of legal requirements involved.

- Good management of public Resources: Human, material, financial and other resources will be properly managed with the coming of Due process in to local government administration.

- Provision of Vital Information: Due process guidelines served as a means of creating awareness' about government activities. It bridges the gap between the common man and those in control of government resources, thereby providing information to all and sundry.

\subsection{Problems associated with Due process implementation}

The paper discovered a number of problems associated with Due process in Nigeria's local government Administration, which includes among others:

- Personalisation: Personal bias of some government official hinders the smooth operation of rules and regulations. In this situation, contracts were been awarded without following the Due procedure of contracts awards.

- Poor Administrative Skills: Existence of some incompetent employees in most local administration results in serious problem, and normally affects Due process activities and hence inability to achieve the overall goal.

- Corruption: Corruption is a social menace that affects almost all fields of human endeavour, more especially public sector of the Nigerian economy. Local government administration is seriously faced with this problem which invariably also affects smooth operation of Due process.

- Favouritism: Favouritism is an act that includes; nepotism, tribalism, sectionalism, god-fatherism, long leg e.t.c. as a means of extending favours, or an act of promoting the interest of others over and above that of the organization. This practice has deprived many local administrations to adapt Due process.

- Poor Leadership: The inability to have good, transparent and dynamic leadership of most local government administration has become a serious impediment to efficiency, productivity and the general goal with a sense of direction and foresight, hence, also affect Due process in local administration.

- Problem of Implementation: A number of laudable programs were initiated by various governments, the problem lies in the government sincerity and commitment to execute those programs. Due process was introduced but there were little effort from government to ensure compliance.

\section{Research Framework}

The literature reviews indicate a direct relationship between Dueprocessand local government administration. Hence, the framework suggest that, Due process activities depend to a large extend on effective local government administration in Nigeria.

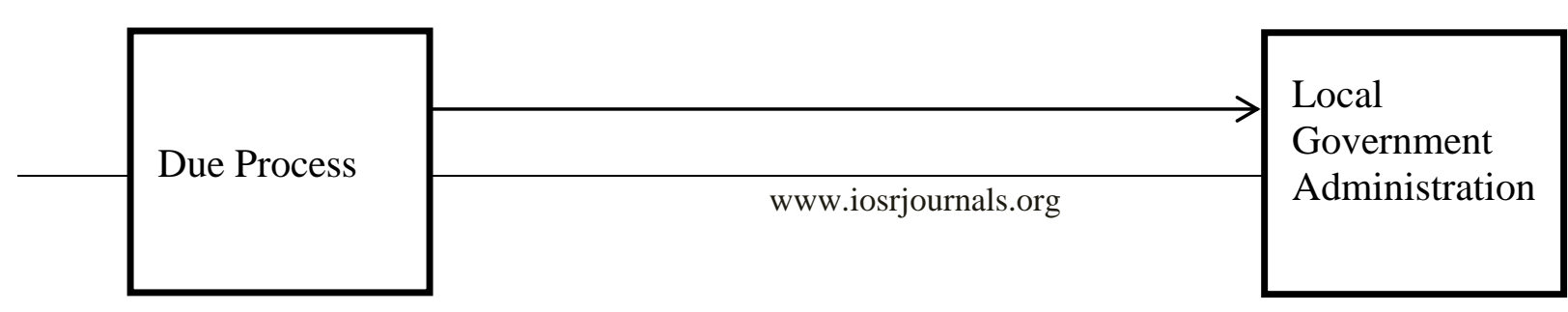




\section{Conclusion}

In this paper, effort has been made to provide a conceptual understanding of Due process as well its application in Nigerian local government administration. Issues related to Due process objectives, strategies, and requirements, conditional issuance of Due process certificate, benefits as well as common problems in Due process implementation were discussed. The paper provided a framework which could serve as the reference model in the relationship between Due process and local government administration. Future studies could examine the empiral relationship between the two constructs

\section{References}

[1]. Adedakun, O.A., Ibironke, O.T., \&Babatunde, S. O., (2013).Assessment of competitive

[2]. tendering methods of procuring educational building projects in Nigeria. Journal of Facilities Management, 11 (1), $81-94$

[3]. Aje, I. (2012). The impact of contractor's prequalification on construction project delivery in

[4]. Nigeria.Engineering, Construction andArchitectural Management, 19 (2), 159-172.

[5]. Apoti, S.A. (2005). Main Features of the Nigerian Public Sector Procurement System: The Due Process Mechanism. A paper presented at the Third Annual International Economic and Management Retreat: held in Accra, Ghana.

[6]. Christodolou, S. (2010).Bid mark-up selection using artificial neural networks and an entropy

[7]. metric.Engineering, Construction and Architectural Management, 17 (4), 424-439.

[8]. Goron-dutse, A.H. (2009). Due Process in Local Government Administration. A paper presented at a workshop organized By Yobe State ministry for local government and chieftaincy Affairs in collaboration with Foem Global consult: held in Damaturu On November 25-27.

[9]. Guidelines on Due Process for Local Government (2006), Kano State

[10]. Ngai, S.C., Drew, D.S., Lo, H.P., \&Skitmore, M. (2002).A theoretical framework for determining the minimum number of bidders in construction bidding competitions.Construction Management and Economics, Vol. 20, pp. 473-82.

[11]. Sa'id, M.M. (2009). The Role of Stakeholders in Due Process. A paper presented at a Two-Day Sensitization workshop for the Commemoration of the International Day Against Corruption: Held in Kano, at Royal Tropicana Hotel on December 22-23, 2009.

[12]. Waara, F., \&Brochner, J. (2006).Price and non-price criteria for contractor selection.Journal of Construction Engineering and Management,132 (8), 797-804. 